\title{
Misdiagnosing Keratoconus
}

\section{David P. Piñero PhD}

To cite this article: David P. Piñero PhD (2015): Misdiagnosing Keratoconus, Expert Review of Ophthalmology, DOI: 10.1586/17469899.2016.1136215

To link to this article: http://dx.doi.org/10.1586/17469899.2016.1136215

Accepted author version posted online: 24 Dec 2015.

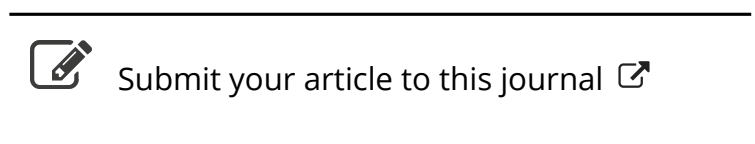

\footnotetext{
LII Article views: 1
}

Q View related articles $₫$

View Crossmark data $\asymp$ 
Publisher: Taylor \& Francis

Journal: Expert Review of Ophthalmology

DOI: $10.1586 / 17469899.2016 .1136215$

\section{MISDIAGNOSING KERATOCONUS}

David P. Piñero, $\mathrm{PhD}^{1,2,3}$

${ }^{1}$ Department of Ophthalmology (OFTALMAR), Vithas Medimar International Hospital,

Alicante, Spain

${ }^{2}$ Foundation for the Visual Quality (FUNCAVIS, Fundación para la Calidad Visual, Alicante, Spain)

${ }^{3}$ Department of Optics, Pharmacology and Anatomy. University of Alicante, Spain.

${ }^{4}$ Optometry and Vision Sciences Unit, Optics Department, University of Valencia, Spain.

Corresponding author:

Dr. David P. Piñero

OFTALMAR, Department of Ophthalmology

Vithas Medimar International Hospital

C/Padre Arrupe, 20

03016 Alicante, Spain

Telf.- +34 965155000

E-mail: david.pinyero@ua.es 


\begin{abstract}
Several diagnostic criteria have been defined for the detection of keratoconus and keratoconus suspect. Most of these criteria are based on the analysis of the anterior and posterior corneal topography and the aberrometric pattern. However, there are corneas without ectasia showing an abnormal topographic and aberrometric pattern compatible with keratoconus. These cases are defined as pseudokeratoconus and can lead to wrong clinical decisions. The main causes of pseudokeratoconus are measurement artefacts, instability of tear film, contact lens warpage and presence of opaque corneal areas or scars. Likewise, some pathological conditions, such as local corneal oedema or corneal inflammatory processes, can be also associated to pseudokeratoconus patterns. A comprehensive analysis of the medical history data and the performance of several clinical tests, including pachymetry or measurement of corneal biomechanical properties, are crucial to avoid misdiagnosing keratoconus.
\end{abstract}




\section{Introduction}

Keratoconus is an ectatic corneal disorder characterized by a usually progressive corneal thinning resulting in corneal protrusion, irregular astigmatism and decreased vision. ${ }^{1}$ In this condition, the cornea adopts a conical shape as a result of the degeneration of the corneal stromal tissue and the subsequent biomechanical alteration. ${ }^{1,2}$ Although corneal topography has been considered a crucial tool for the diagnosis of keratoconus, other devices and parameters are also useful, especially in incipient or subclinical forms. ${ }^{3,4}$ Pachymetric, posterior corneal elevation, anterior chamber depth, aberrometric and corneal biomechanical data have demonstrated to be very useful for keratoconus diagnosis. ${ }^{4}$

Currently, the detection of moderate and advanced keratoconus is not a difficult task using corneal topography in combination with the analysis of biomicroscopic, retinoscopic and pachymetric signs. ${ }^{1}$ A more difficult task is the detection of very early or preclinical stages of keratoconus and for this reason different approaches have been developed for such purpose. ${ }^{5-9}$ Specifically, the term "keratoconus suspect" was coined for defining those corneas without biomicroscopic keratoconic signs but subtle topographic features similar to early stages of keratoconus. ${ }^{10-13}$ Current advances in diagnostic technologies allow the clinician to detect almost all types of keratoconus. ${ }^{4}$ However, misdiagnosing keratoconus is still possible when a an asymmetric anterior corneal topographic pattern similar to those of ectatic corneas is present. ${ }^{14-22}$ These topographic patterns are defined as pseudokeratoconus. ${ }^{14-22}$ The aim of the current review was to summarize the diagnostic criteria of keratoconus and keratoconus suspect based on the global consensus ${ }^{23}$ and to define the potential sources of keratoconus misdiagnosis due to the presence pseudokeratoconus patterns and how to detect them. 


\section{Diagnosis of keratoconus}

\section{Anterior corneal profile}

The typical topographic map of a keratoconus displays a well-delimited zone with a high dioptric value, surrounded by progressively decreasing curvature zones (Figure 1). Although the cone vertex can be located at the superior ${ }^{24}$ and central portion of the cornea, ${ }^{25}$ it is displaced in most of cases towards the lower mid-peripheral region. ${ }^{4}$ Therefore, the topographic map of the anterior corneal surface displays a vertical asymmetry, with the following peculiarities:

-Focal steepening located in the cone protrusion zone surrounded by concentric decreasing power zones.

-Infero-superior (I-S) asymmetry within the mid-peripheral cornea. Special attention should be taken when obtaining values of the I-S index above 1.4 D.

-Angling of the hemi-meridians in the bow-tie pattern. Keratoconus must be suspected especially when this angling exceeds 20 or 30 degrees in relation to the vertical meridian.

Different diagnostic approaches have been developed considering these peculiarities of the anterior corneal topographic profile in keratoconus, including the definition of specific indices (Table 1), ${ }^{26-40}$ neural networks ${ }^{34,41-43}$ and mathematical algorithms of corneal shape reconstruction. ${ }^{44-48}$ The digital analysis of the image of the Placido disks projected on the cornea has been also shown to be a valid tool for keratoconus diagnosis, avoiding the use of estimated data or parameters obtained indirectly. ${ }^{49}$ In addition, the analysis of corneal asphericity (Q) has been shown to be of potential usefulness in the detection of keratoconus (Figure 1), as the anterior protrusion generates an increase of the corneal prolatism, with an associated negativization of $\mathrm{Q}^{50-52}$ More marked negative asphericity (significant prolateness) for the anterior corneal surface has been found in some studies comparing some topographic features of normal and keratoconus eyes. ${ }^{50-52}$ Specifically, mean Q values of $-0.29 \pm 0.09,-0.65 \pm 0.27$, and 
$-1.18 \pm 0.32$ have been reported in a sample of normal, keratoconus grade I and keratoconus grade II eyes (Amsler-Krumeich classification), respectively. ${ }^{52}$

\section{Posterior corneal elevation in keratoconus}

Significantly larger values of best fit sphere $(\mathrm{BFS})^{10,12,53}$ and highest posterior elevation ${ }^{11,12,54}$ have been found in keratoconus (Figure 2). Schlegel ${ }^{12}$ et al found in a sample of 48 keratoconus-suspect patients a mean maximum posterior elevation of $0.0288 \pm 0.0102 \mu \mathrm{m}$ at $1 \mathrm{~mm}$ of radius from the centre using the scanning-slit technology. Fam and $\mathrm{Lim}^{55}$ defined the posterior elevation ratio as the ratio of the maximum posterior elevation in the central 5-mm corneal zone to the BFS for the posterior cornea, obtaining a mean value for this ratio of $1.874 \pm$ 0.532 in a sample of 43 keratoconus patients and of $1.103 \pm 0.462$ in a sample of 23 keratoconus suspects using also the scanning-slit technology. ${ }^{55}$ For a cut-off point of 0.5122 , these authors obtained sensitivity and specificity values of $99 \%$ and $95.2 \%$ for the detection of keratoconus. ${ }^{55}$ De Sanctis and colleagues ${ }^{10}$ found cut-off values of the maximum posterior corneal elevation measured in the 5-mm central zone of $35 \mu \mathrm{m}$ (sensitivity 97.3\%, specificity 96.9\%) and $29 \mu \mathrm{m}$ (sensitivity 68\%, specificity $90.8 \%$ ) for the detection of clinical and subclinical keratoconus using a Scheimpflug photography-based system.

\section{Corneal aberrometry}

Higher amounts of vertical coma and larger values of coma-like root mean square (RMS) have been reported in patients with keratoconus or keratoconus suspect ${ }^{2,5,51,56-59}$ (Figure 3). Bühren et $\mathrm{al}^{5}$ found cut-off points of primary coma root mean square (RMS) of 0.555 (sensitivity $100 \%$, specificity $98.4 \%$ ) and $0.248 \mu \mathrm{m}$ (sensitivity $100 \%$, specificity $73.6 \%$ ) for the detection of clinical and subclinical keratoconus, respectively. Similarly, the levels of primary coma have been also found to be significantly elevated in the posterior corneal surface. ${ }^{60,61}$ Nakagawa et $\mathrm{al}^{60}$ found in a sample of 28 keratoconic eyes large amounts of primary coma in the anterior and posterior corneal surfaces (primary coma RMS anterior/posterior: 3.57 
/ $0.87 \mu \mathrm{m}$ ), although coma from the posterior surface compensated partly for that from the anterior surface.

\section{Pachymetric analysis in keratoconus}

Current imaging technology allows the clinician to obtain pachymetric maps providing information point-by-point of the entire cornea. ${ }^{3,4}$ A more detailed and accurate control of the progression of an ectatic disorder can be performed with systems, such as those based on Scheimpflug photography, optical coherence tomographers or very high frequency ultrasonography systems. ${ }^{3,4}$ It should be considered that the term corneal topography is used for defining the 2-D analysis of the anterior corneal shape whereas corneal tomography is used for the examination of the front and back surfaces of the cornea, along with pachymetric mapping, considering it computes a three-dimensional image of the cornea.

Differences in the progression of corneal thickness from centre to periphery have been found between normal and clinical and subclinical keratoconus eyes. ${ }^{63-68}$ Saad and Gatinel ${ }^{66}$ found that the percentage of thickness increase from the thinnest point to the periphery measured using the scanning slit-technology as well as the percentage of variation of anterior and posterior curvatures oyer the entire cornea centered on the thinnest point were able to detect very mild forms of ectasia undetected by a Placido-based neural network program. Ambrosio et $\mathrm{al}^{65}$ demonstrated that pachymetric progression indices obtained with the Pentacam system were better factors to differentiate between normal and keratoconic corneas than single-point pachymetric measurements. In addition, the analysis of the epithelial thickness profile (epithelial doughnut pachymetric pattern) has been shown to be also useful for keratoconus detection and characterization. ${ }^{69}$

\section{Corneal biomechanics in keratoconus}

Two different systems are currently available for the analysis of corneal biomechanics in clinical practice: Ocular Response Analyzer (ORA) (Reichert) and CorVis ST system (Oculus).$^{70}$ Concerning the main biomechanical parameters provided by the ORA system, 
corneal hysteresis $(\mathrm{CH})$ and corneal resistance factor (CRF), they have shown moderate diagnostic ability for keratoconus detection. ${ }^{71,72}$ Fontes et $\mathrm{al}^{72}$ obtained a poor overall predictive accuracy of CH (cutoff, 9.64 mmHg; sensitivity, 87\%; specificity, 65\%; test accuracy, 74.83\%) and CRF (cutoff, $9.60 \mathrm{mmHg}$; sensitivity, 90.5\%; specificity, 66\%; test accuracy, 76.97\%) for detecting mild keratoconus. New parameters based on the analysis of the response signal curve obtained with the ORA system have improved the diagnostic ability of this device for keratoconus detection. ${ }^{73}$ Regarding the CorVis ST system, some limitations in the diagnostic ability of the parameters provided by this device have been reported. ${ }^{75-77}$ Tian et al ${ }^{75}$ found that the deformation amplitude was the best predictive parameter, with a sensitivity of $81.7 \%$, although there was a significant overlap between keratoconic and normal corneas that ranged from 1.0 to $1.4 \mathrm{~mm}$.

\section{Pseudokeratoconus topographic pattern}

Four different conditions can lead to the measurement of topographic patterns compatible with keratoconus that are not representing a real ectatic condition: measurement artefacts, instability of tear film, contact lens warpage and presence of corneal areas with a loss of transparency or scars. Pseudokeratoconus displays some topographic features that are compatible with keratoconus, including areas of local corneal steepening, significant negative corneal asphericity, high values of posterior corneal elevation and astigmatism, and abnormally increased levels of anterior and posterior corneal aberrations. ${ }^{14-22}$

\section{Pseudokeratoconus due to measurement artefacts}

Some acquisition artefacts with currently available corneal topography systems and tomographers can lead to erroneous measurements and incorrect interpretations by the device used for corneal analysis. These artefacts can be generated by incorrect patient positioning during measurement. Hick and coauthors ${ }^{15}$ found that rotational misalignment during measurement with the scanning slit technology was able to induce corneal asymmetry on 
elevation and curvature maps and, consequently, pseudokeratoconus patterns. Hubbe and Foulks $^{20}$ demonstrated that a change in relative steepness with a Placido disk topographer produced a pattern that mimics keratoconus that could be seen at deviations of less than 5 degrees in some patients. It has been also shown the influence of eyelids in the anterior corneal shape when performing continuing pressure on them due to different gaze positions. ${ }^{78}$ Therefore, it is important to check and control the patient position during the topographic measurement and to take three consecutive measurements if possible in order to confirm the consistency of the measurements obtained.

\section{Pseudokeratoconus due to tear film instability}

Tear film alterations are one of the most relevant factors leading to artefacts in a topographic examination, especially in those analysing object patterns projected on the cornea. A low tear film quality (low scores of the break-up time, BUT) or quantity (low Schirmer test values) can be associated to alterations in the anterior corneal surface (Figure 5), such as epitheliopathies which can contribute to obtain altered topographic patterns. ${ }^{79}$ Cheng et $\mathrm{al}^{16}$ reported the case of a patient with soft contact lens-induced keratopathy in which the slit scanning corneal topography showed features suggestive of keratoconus. It is then recommendable to perform the topographic acquisition after an eye blink and to confirm the consistency of measurement in cases of dry eye by taking three consecutive measurements.

\section{Pseudokeratoconus due to contact lens warpage}

Contact lens wear may alter significantly the anterior corneal topographic pattern, especially with rigid gas-permeable contact lenses. It should be considered that rigid gaspermeable contact lenses as well as some silicone hydrogels have a higher rigidity module and their bearing on the cornea can cause some transitory effect (Figure 5). Tseng et $\mathrm{al}^{80}$ documented a case in which a diagnosis of suspect keratoconus was made based on the corneal topographic map in a hydrogel contact lens wearer. At 8 weeks after the cessation of the contact 
lens wear, corneal topography showed a normal pattern, confirming that a corneal warpage was previously present mimicking keratoconus. ${ }^{80}$

\section{Pseudokeratoconus due to loss of corneal transparency or scars}

As all available topographic systems are based on optical principles, the presence of corneal areas with a loss of transparency may also lead to the obtaining of wrong data, especially when measurements are obtained with the scanning slit technology. Eurthermore, scars or leukomas can generate areas of local flattening with the corresponding steepening of the adjacent areas leading to a pattern of pseudokeratoconus (Figure 6). Therefore, it is important to consider the level of transparency of the cornea and the medical history of the patient when interpreting a corneal topographic map showing a pattern compatible with a keratoconus.

\section{Pseudokeratoconus due to other causes}

There are some pathological conditions that can lead to the presence of topographic patterns compatible with keratoconus that disappear when the condition is treated. Localized changes in corneal thickness due to endothelial-Descemet membrane disruption ${ }^{14}$ or inflammatory processes ${ }^{18}$ can induce a pseudokeratoconus topographic pattern. Likewise, Dursun et al ${ }^{18}$ demonstrated that chronic ocular rosacea can generate an inferior corneal thinning and high astigmatism associated to a pseudokeratoconus pattern. These authors suggested that the inferior pattern of thinning in rosacea may be related to chronic exposure of the inferior cornea to inflammatory and matrix-degrading factors in the inferior tear meniscus. ${ }^{18}$

\section{Tools for avoiding misdiagnosing of keratoconus}

The diagnosis of keratoconus should not only be based in the analysis of the topographic pattern of the anterior corneal surface as this can lead to misdiagnosing. Indeed, there is no topographic parameter providing $100 \%$ of sensitivity and specificity for the detection of keratoconus, especially in subclinical forms. The combination of several clinical tests is 
essential for an accurate detection and a complete characterization of a case of keratoconus. ${ }^{4}$ The medical history of the patient must be considered before providing a final and consistent diagnosis of a ectatic condition. Likewise, other evaluations besides corneal topography and aberrometry should be considered for an adequate diagnosis of keratoconus, such as the evaluation of corneal thickness, biomechanical properties or volume. ${ }^{4}$ Recent research on keratoconus are focused on defining prediction models for the detection of keratoconus according to a variety of clinical parameters. ${ }^{4}$ Montalbán et $\mathrm{al}^{50}$ found by means of logistic regression analysis that the 8-mm anterior shape factor, the anterior chamber depth, and the minimal corneal thickness were significant independent predictors of the presence of keratoconus $(\mathrm{p}<0.01)$. With the same type of statistical analysis, Uçakhan et $\mathrm{al}^{81}$ found that the combined analysis of anterior and posterior corneal power, elevation, and thickness data provided by a Scheimpflug imaging device effectively discriminated between ectatic corneas and normal corneas. Kovacs and colleagues ${ }^{82}$ defined a threshold level of posterior corneal elevation $(40 \mu \mathrm{m})$ and corneal thickness $(450 \mu \mathrm{m})$ beyond which the level of corneal protrusion in keratoconus accelerates. All these predictive models confirm the relevance of corneal thickness in the detection of keratoconus.

\section{Conclusions}

In conclusion, there are topographic patterns with similar features compatible with keratoconus but not representing a real corneal ectatic condition that can lead to misdiagnosing keratoconus. These cases are defined as pseudokeratoconus and must be identified properly in order to avoid taking wrong clinical decisions. Measurement artefacts, the instability of the tear film, the presence of contact lens warpage and the presence of corneal areas with a loss of transparency or scars are the main causes of pseudokeratoconic patterns. Likewise, some pathological conditions affecting corneal thickness can be associated to topographic patterns compatible with keratoconus. Clinical analyses in these cases should be complemented with other clinical tests, such as pachymetry or measurement of corneal biomechanical properties, 
and with a comprehensive analysis of medical history data in order to perform a correct clinical diagnosis.

\section{EXPERT COMMENTARY:}

Currently, advances in diagnostic technologies allow clinicians to perform more accurate diagnosis of keratoconus, even in its incipient stages. The combination of the analysis of the anterior and posterior corneal topographic map, the pachymetric profile, biomicroscopic signs and corneal biomechanical properties provides an integrated analysis of the corneal structure, minimizing the number of wrong diagnostic decisions in terms of keratoconus detection. In spite of all these advances, there is still a possibility of misdiagnosing keratoconus due mainly to the presence of anterior corneal topographic patterns similar to those of ectatic corneas, which are defined as pseudokeratoconus. Measurement artifacts, the instability of the tear film, the presence of contact lens warpage and the presence of corneal areas with a loss of transparency or scars are the main causes of this type of patterns. The combination of the analysis of corneal topography with other clinical tests is crucial to avoid this type of misdiagnosing.

\section{FIVE-YEAR VIEW:}

In next five years, the incidence of keratoconus misdiagnosis due to pseudokeratoconus patterns will be dramatically minimized as new topographic devices are being developed and introduced in clinical practice that combine different technologies to obtain more information about the corneal structure, not only the analysis of the anterior corneal topographic pattern. The diagnosis of keratoconus will be based on a concept of integrated analysis with the combination of different clinical parameters, not only on the analysis of corneal topography.

\section{KEY ISSUES:}


-Different diagnostic approaches have been developed for keratoconus considering the peculiarities of the anterior corneal topographic pattern in this condition, including the definition of specific indexes, neural networks and mathematical algorithms of corneal shape reconstruction.

-The analysis of the topographic profile of the posterior corneal surface has been also shown to be a useful tool for diagnosis of keratoconus, with significantly larger values of best fit sphere and highest elevation for this surface in this corneal condition.

-The level of vertical coma and coma-like aberrations can be used as additional criteria for the detection of keratoconus or keratoconus suspect.

-The analysis of corneal biomechanical properties with the Ocular Response Analyzer or the CorVis ST system can be useful for complementing the diagnosis of keratoconus, although the sensitivity and specificity for keratoconus detection of the biomechanical parameters provided by these instruments are somewhat limited.

-There are topographic patterns compatible with keratoconus, including areas of local corneal steepening and significant negative corneal asphericity, which are not representing a real ectatic condition. These patterns are defined as pseudokeratoconus.

-There are four factors leading to pseudokeratoconus topographic patterns: measurement artifacts, instability of tear film, contact lens warpage and presence of corneal areas with a loss of transparency or scars.

-There are some pathological conditions that can also lead to pseudokeratoconus patterns, especially when localized changes in corneal thickness are present due to endothelialDescemet membrane disruption or inflammatory processes.

-Integrated analyses of the results of different clinical tests as well as of the medical history data are crucial to perform an appropriate diagnosis and to avoid misdiagnosing keratoconus. 


\section{Financial \& competing interests disclosure}

The author has no relevant affiliations or financial involvement with any organization or entity with a financial interest in or financial conflict with the subject matter or materials discussed in the manuscript. This includes employment, consultancies, honoraria, stock ownership or options, expert testimony, grants or patents received or pending, or royalties.

\section{References}

1.- Rabinowitz YS. Keratoconus. Surv Ophthalmol 1998; 42: 297-319.

2.- Piñero DP, Alió JL, Barraquer RI, Michael R, Jiménez R. Corneal biomechanics, refraction, and corneal aberrometry in keratoconus: an integrated study. Invest Ophthalmol Vis Sci 2010; 51: $1948-55$.

3.- Piñero DP. Technologies for anatomical and geometric characterization of the corneal structure and anterior segment: a review. Semin Ophthalmol 2015; 30: 161-70.

4.- Piñero DP, Nieto JC, Lopez-Miguel A. Characterization of corneal structure in keratoconus. J Cataract Refract Surg 2012; 38: 2167-83,

5.- Bühren J, Schäffeler $\mathrm{T}$, Kohnen $\mathrm{T}$. Validation of metrics for the detection of subclinical keratoconus in a new patient collective. J Cataract Refract Surg 2014; 40: 259-68.

6.- Smadja D, Touboul D, Cohen A, Doveh E, Santhiago MR, Mello GR, Krueger RR, Colin J. Detection of subclinical keratoconus using an automated decision tree classification. Am J Ophthalmol 2013, 156: 237-246.e1.

7.- Ramos-López D, Martínez-Finkelshtein A, Castro-Luna GM, Burguera-Gimenez N, VegaEstrada A, Piñero D, Alió JL. Screening subclinical keratoconus with placido-based corneal indices. Optom Vis Sci 2013; 90: 335-43.

8.- Arbelaez MC, Versaci F, Vestri G, Barboni P, Savini G. Use of a support vector machine for keratoconus and subclinical keratoconus detection by topographic and tomographic data. Ophthalmology 2012; 119: 2231-8. 
9.- Bühren J, Kook D, Yoon G, Kohnen T. Detection of subclinical keratoconus by using corneal anterior and posterior surface aberrations and thickness spatial profiles. Invest Ophthalmol Vis Sci 2010; 51: 3424-32.

10.- De Sanctis U, Loiacono C, Richiardi L, Turco D, Mutani B, Grignolo FM. Sensitivity and specificity of posterior corneal elevation measured by Pentacam in discriminating keratoconus/subclinical keratoconus. Ophthalmology 2008; 115: 1534-9.

11.- Nilforoushan MR, Speaker M, Marmor M, Abramson J, Tullo W, Morschauser D, Latkany

R. Comparative evaluation of refractive surgery candidates with Placido topography, Orbscan

II, Pentacam, and wavefront analysis. J Cataract Refract Surg 2008; 34: 623-31.

12.- Schlegel Z, Hoang-Xuan T, Gatinel D. Comparison of and correlation between anterior and posterior corneal elevation maps in normal eyes and keratoconus-suspect eyes. J Cataract Refract Surg 2008; 34: 789-95.

13.- Bühren J, Kühne C, Kohnen T. Defining subclinical keratoconus using corneal first-surface higher-order aberrations. Am J Ophthalmol 2007; 143: 381-9.

14.- Limpas Y, Schauer P, Vignal R, Wary P. [Oedema with acute pseudokeratoconus corneal aspect in a case of Kearns-Sayre syndrome]. J Fr Ophtalmol 2009; 32: 577.e1-5.

15.- Hick S, Laliberté JF, Meunier J, Chagnon M, Brunette I. Effects of misalignment during corneal topography. J Cataract Refract Surg 2007; 33: 1522-9.

16.- Cheng HC, Lin KK, Chen YF, Hsiao CH. Pseudokeratoconus in a patient with soft contact lens-induced keratopathy: assessment with Orbscan I. J Cataract Refract Surg 2004; 30: 925-8.

17.- Stoesser F, Lévy D, Moalic S, Colin J. [Pseudokeratoconus and ocular rosacea]. J Fr Ophtalmol 2004; 27: 278-84.

18.- Dursun D, Piniella AM, Pflugfelder SC. Pseudokeratoconus caused by rosacea. Cornea 2001; 20: 668-9.

19.- Mandell RB, Chiang CS, Yee L. Asymmetric corneal toricity and pseudokeratoconus in videokeratography. J Am Optom Assoc 1996; 67: 540-7.

20.- Hubbe RE, Foulks GN. The effect of poor fixation on computer-assisted topographic corneal analysis. Pseudokeratoconus. Ophthalmology 1994;101: 1745-8. 
21.- Mathys B. [Pseudokeratoconus: a topical finding?]. Bull Soc Belge Ophtalmol 1993; 249: $113-6$

22.- Lang GK, Holbach L, Schlötzer U. [Pseudokeratoconus in trisomy 21 and posterior polymorphous corneal dystrophy]. Klin Monbl Augenheilkd 1989; 195: 95-9.

23.- Gomes JA, Tan D, Rapuano CJ, Belin MW, Ambrósio R Jr, Guell JL, Malecaze F, Nishida K, Sangwan VS; Group of panellists for the Global Delphi Panel of Keratoconus and Ectatic Diseases. Global consensus on keratoconus and ectatic diseases. Cornea 2015; 34: 359-69.

24.- Rogers GJ, Attenborough M. Bilateral superior keratoconus: two case reports. Eye (Lond) 2014; 28: 1254-7.

25.- Prakash G, Srivastava D, Choudhuri S, Thirumalai SM, Bacero R. Differences in central and non-central keratoconus, and their effect on the objective screening thresholds for keratoconus. Acta Ophthalmol. 2015 Nov 2. doi: 10.1111/aos.12899. [Epub ahead of print]. 26.- Piñero DP, Pérez-Cambrodí RJ, Soto-Negro R, Ruiz-Fortes P, Artola A. Clinical utility of ocular residual astigmatism and topographic disparity vector indexes in subclinical and clinical keratoconus. Graefes Arch Clin Exp Ophthalmol. 2015 Sep 7. [Epub ahead of print]

27.- Kopacz D, Maciejewicz P, Kecik D. [The use of Pentacam for keratoconus diagnosis and progress evaluation]. Klin Oczna 2011; 113: 75-81.

28.- Abad JC, Rubinfeld RS, Del Valle M, Belin MW, Kurstin JM. Vertical D. A novel topographic pattern in some keratoconus suspect. Ophthalmology 2007; 114: 1020-6.

29.- Hansen DW. Evaluating the eye with corneal topography. Contact Lens Spectrum 2003; 18: $27-32$.

30.- Shiotani Y, Maeda N, Inoue T, Watanabe H, Inoue Y, Shimomura Y, Tano Y. Comparison of topographic indices that correlate with visual acuity in videokeratography. Ophthalmology 2000; 107: 559-64.

31.- Rabinowitz YS, Rasheed K. KISA\% index: a quantitative videokeratography algorithm embodying minimal topographic criteria for diagnosis keratoconus. J Cataract Refract Surg 1999; 25: 1327-35. 
32.- Dastjerdi MH, Hashemi H. A quantitative corneal topography index for detection of keratoconus. J Refract Surg 1998; 14: 427-36.

33.- Holladay JT. Corneal topography using the Holladay Diagnostic Summary. J Cataract Refract Surg 1997; 23: 209-21.

34.- Smolek MK, Klyce SD. Current keratoconus detection methods compared with a neural network approach. Invest Ophthalmol Vis Sci 1997; 38: 2290-9.

35.- Rabinowitz YS. Videokeratographic indices to aid in screening for keratoconus. J Refract Surg 1995; 11: 371-9.

36.- Rabinowitz YS. Corneal topography. Curr Opin Ophthalmol 1995; 6: 57-62.

37.- Maeda N, Klyce SD, Smolek MK. Comparison of methods for detecting keratoconus using videokeratography. Arch Ophthalmol 1995; 113: 870-4.

38.- Twa MD, Parthasarathy S, Roberts C, Thomas M, Raasch TW, Bullimore MA. Automated decision tree classification of corneal shape. Optom Vis Sci 1995; 82: 1038-46.

39.- Maeda N, Klyce SD, Smolek MK, Thompson HW. Automated keratoconus screening with corneal topography analysis. Invest Ophthalmol Vis Sci 1994; 35: 2749-57.

40.- Wilson SE, Klyce SD. Quantitative descriptors of corneal topography. A clinical study. Arch Ophthalmol 1991; 109: 349-53.

41.- Carvalho LA. Preliminary results of neural networks and Zernike polynomials for classification of videokeratography maps. Optom Vis Sci 2005; 82: 151-8.

42.- Accardo PA, Pensiero S. Neural network-based system for early keratoconus detection from corneal topography. J Biomed Inform 2002; 35: 151-9.

43.- Smolek MK, Klyce SD. Current keratoconus detection methods compared with a neural network approach.Invest Ophthalmol Vis Sci. 1997 Oct;38(11):2290-9.

44.- Martinez-Finkelshtein A, Delgado AM, Castro GM, Zarzo A, Alió JL. Comparative analysis of some modal reconstruction methods of the shape of the cornea from corneal elevation data. Invest Ophthalmol Vis Sci 2009; 50: 5639-45. 
45.- Yoon G, Pantanelli S, MacRae S. Comparison of Zernike and Fourier wavefront reconstruction algorithms in representing corneal aberration of normal and abnormal eyes. $\mathrm{J}$ Refract Surg 2008; 24: 582-90.

46.- Carvalho LA. Accuracy of Zernike polynomials in characterizing optical aberrations and the corneal surface of the eye. Invest Ophthalmol Vis Sci 2005; 46: 1915-26.

47.- Smolek MK, Klyce SD. Goodness-of-prediction of Zernike polynomials fitting to corneal surfaces. J Cataract Refract Surg 2005; 31: 2350-5.

48.- Iskander R, Collins MJ, David B. Optimal modeling of corneal surface-with Zernike polynomials. IEEE Trans Biomed Eng 2001; 48: 87-95.

49.- Ramos-López D, Martínez-Finkelshtein A, Castro-Luna GM, Piñero D, Alió JL. PlacidoBased Indices of Corneal Irregularity. Optom Vis Sci 2011; 88: 1220-31.

50.- Montalbán R, Alio JL, Javaloy J, Piñero DP. Comparative analysis of the relationship between anterior and posterior corneal shape analyzed by Scheimpflug photography in normal and keratoconus eyes. Graefes Arch Clin Exp Ophthalmol 2013; 251: 1547-55.

51.- Alió JL, Piñero DP, Alesón A, Teus MA, Barraquer RI, Murta J, Maldonado MJ, Castro de Luna G, Gutiérrez R, Villa C, Uceda-Montanes A. Keratoconus-integrated characterization considering anterior corneal aberrations, internal astigmatism, and corneal biomechanics. J Cataract Refract Surg 2011; 37: 552-68.

52.- Piñero DP, Alió JL, Alesón A, Escaf M, Miranda M. Corneal volume, pachymetry, and correlation of anterior and posterior corneal shape in subclinical and different stages of clinical keratoconus. J Cataract Refract Surg 2010; 36: 814-25.

53.- Sonmez B, Doan MP, Hamilton R. Identification of scanning slit-beam topographic parameters important in distinguishing normal from keratoconic corneal morphologic features. Am J Ophthalmol 2007; 143: 401-8.

54.- Rao SN, Raviv T, Majmudar PA, Epstein RJ. Role of Orbscan II in screening keratoconus suspects before refractive corneal surgery. Ophthalmology 2002; 109: 1642-6.

55.- Fam, H-B, Lim KL. Corneal elevation indices in normal and keratoconic eyes. J Cataract Refract Surg 2006; 32: 1281-7. 
56.- Piñero DP, Alió JL, Alesón A, Escaf M, Miranda M. Pentacam posterior and anterior corneal aberrations in normal and keratoconic eyes. Clin Exp Optom 2009; 92: 297-303.

57.- Alió JL, Shabayek MH. Corneal higher order aberrations: a method to grade keratoconus. J Refract Surg 2006; 22: 539-45.

58.- Gobbe M, Guillon M. Corneal wavefront aberration measurements to detect keratoconus patients. Con Lens Anterior Eye 2005; 28: 57-66.

59.- Applegate RA, Hilmantel G, Howland HC, Tu EY, Starck T, Zayac EJ. Corneal first surface optical aberrations and visual performance. J Refract Surg 2000; 16: 507-14.

60.- Nakagawa T, Maeda N, Kosaki R, Hori Y, Inoue T, Saika M, Mihashi T, Fujikado T, Tano Y. Higher-order aberrations due to the posterior corneal surface in patients with keratoconus. Invest Ophthalmol Vis Sci 2009; 50: 2660-5.

61.- Chen M, Yoon G. Posterior corneal aberrations and their compensation effects on anterior corneal aberrations in keratoconic eyes. Invest Ophthalmol Vis Sci 2008; 49: 5645-52.

62.- Ambrósio R Jr, Belin MW. Imaging of the cornea: topography vs tomography. J Refract Surg 2010; 26: 847-9.

63.- Cui J, Zhang X, Hu Q, Zhou WY, Yang F. Evaluation of corneal thickness and volume parameters of subclinical keratoconus using a Pentacam Scheimflug system. Curr Eye Res. 2015 Nov 25:1-4. [Epub ahead of print].

64.- Demir S, Ortak H, Yeter V, Alim S, Sayn O, Taş U, Sönmez B. Mapping corneal thickness using dual-scheimpflug imaging at different stages of keratoconus. Cornea 2013; 32: $1470-4$.

65.- Ambrósio R Jr, Caiado AL, Guerra FP, Louzada R, Roy AS, Luz A, Dupps WJ, Belin MW. Novel pachymetric parameters based on corneal tomography for diagnosing keratoconus. J Refract Surg 2011; 27: 753-8.

66.- Saad A, Gatinel D. Topographic and tomographic properties of forme fruste keratoconus corneas. Invest Ophthalmol Vis Sci. 2010; 51: 5546-55. 
67.- Li Y, Meisler DM, Tang M, Lu AT, Thakrar V, Reiser BJ, Huang D. Keratoconus diagnosis with optical coherence tomography pachymetry mapping. Ophthalmology 2008;115: 2159-66.

68.- Ambrosio R Jr, Alonso RS, Luz A, Coca Velarde LG. Corneal-thickness spatial profile and corneal-volume distribution: tomographic indices to detect keratoconus. J Cataract Refract Surg 2006; 32: 1851-9.

69.- Reinstein DZ, Archer TJ, Gobbe M. Corneal epithelial thickness profile in the diagnosis of keratoconus. J Refract Surg 2009; 25: 604-10.

70.- Piñero DP, Alcón N. In vivo characterization of corneal biomechanics. J Cataract Refract Surg 2014; 40: 870-87.

71.- Galletti JG, Pförtner T, Bonthoux FF. Improved keratoconus detection by Ocular Response Analyzer testing after consideration of corneal thickness as a confounding factor. J Refract Surg 2012; 28: 202-8.

72.- Fontes BM, Ambrósio R Jr, Jardim D, Velarde GC, Nosé W. Corneal biomechanical metrics and anterior segment parameters in mild keratoconus. Ophthalmology 2010; 117; 673-9. 73.- Touboul D, Bénard A, Mahmoud AM, Gallois A, Colin J, Roberts CJ. Early biomechanical keratoconus pattern measured with an ocular response analyzer: curve analysis. J Cataract Refract Surg. 2011; 37:2144-50.

74.- Luz A, Fontes BM, Lopes B, Ramos I, Schor P, Ambrósio R Jr. ORA waveform-derived biomechanical parameters to distinguish normal from keratoconic eyes. Arq Bras Oftalmol 2013, 76: 111-7.

75.- Tian L, Huang YF, Wang LQ, Bai H, Wang Q, Jiang JJ, Wu Y, Gao M. Corneal biomechanical assessment using corneal visualization scheimpflug technology in keratoconic and normal eyes. J Ophthalmol 2014; 2014: 147516.

76.- Ali NQ, Patel DV, McGhee CN. Biomechanical responses of healthy and keratoconic corneas measured using a noncontact scheimpflug-based tonometer. Invest Ophthalmol Vis Sci 2014; 55: 3651-9. 
77.- Tian L, Ko MW, Wang LK, Zhang JY, Li TJ, Huang YF, Zheng YP. Assessment of ocular biomechanics using dynamic ultra high-speed Scheimpflug imaging in keratoconic and normal eyes. J Refract Surg 2014; 30: 785-91.

78.- Collins MJ, Buehren T, Trevor T, Statham M, Hansen J. Factors influencing lid pressure on the cornea. Eye Contact Lens 2006; 32: 168-73.

79.- Paiva CS, Harris LD, Plugfelder SC. Keratoconus-like topographic changes in keratoconjuctivitis sicca. Cornea 2003; 22: 22-4.

80.- Tseng SS, Hsiao JC, Chang DC. Mistaken diagnosis of keratoconus because of corneal warpage induced by hydrogel lens wear. Cornea 2007; 26: 1153-5.

81.- Uçakhan ÖÖ, Cetinkor V, Özkan M, Kanpolat A. Evaluation of Scheimpflug imaging parameters in subclinical keratoconus, keratoconus, and normal eyes. J Cataract Refract Surg. 2011; 37: 1116-24.

82.- Kovács I, Miháltz K, Németh J, Nagy ZZ. Anterior chamber characteristics of keratoconus assessed by rotating Scheimpflug imaging. J Cataract Refract Surg 2010; 36: 1101-6. 


\section{Figure legends}

Figure 1.- Sagittal curvature map of a keratoconus cornea obtained by a rotating Scheimpflug camera-based topography system.

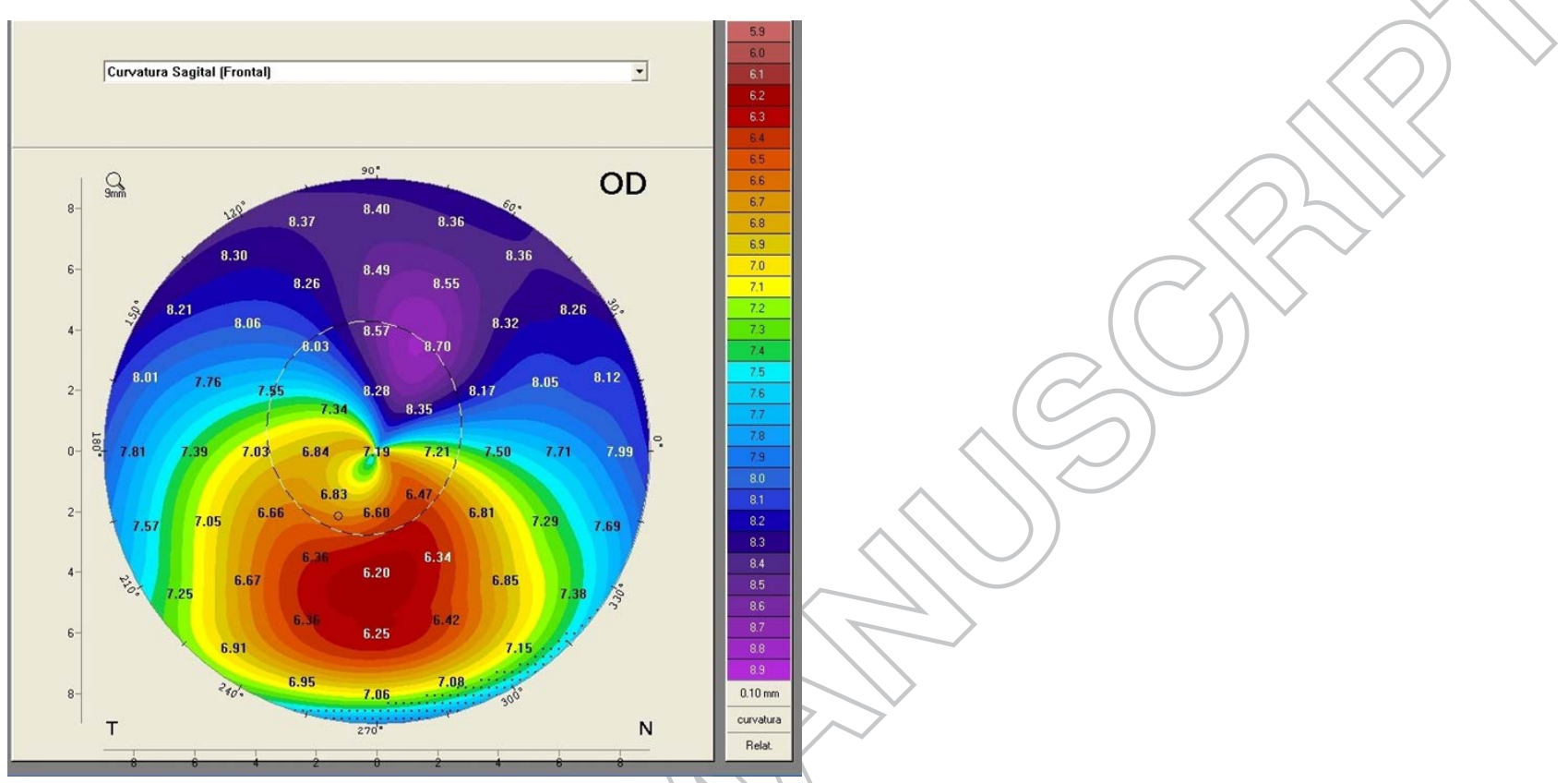

Figure 2.- Corneal analysis in a keratoconus eye with the Scheimpflug-based topography system

Sirius from CSO (Italy). Four maps are displayed: pachymetric map (up-left), anterior tangential map (up-right), anterior eleyation map (down-left), and posterior elevation map (down-right).

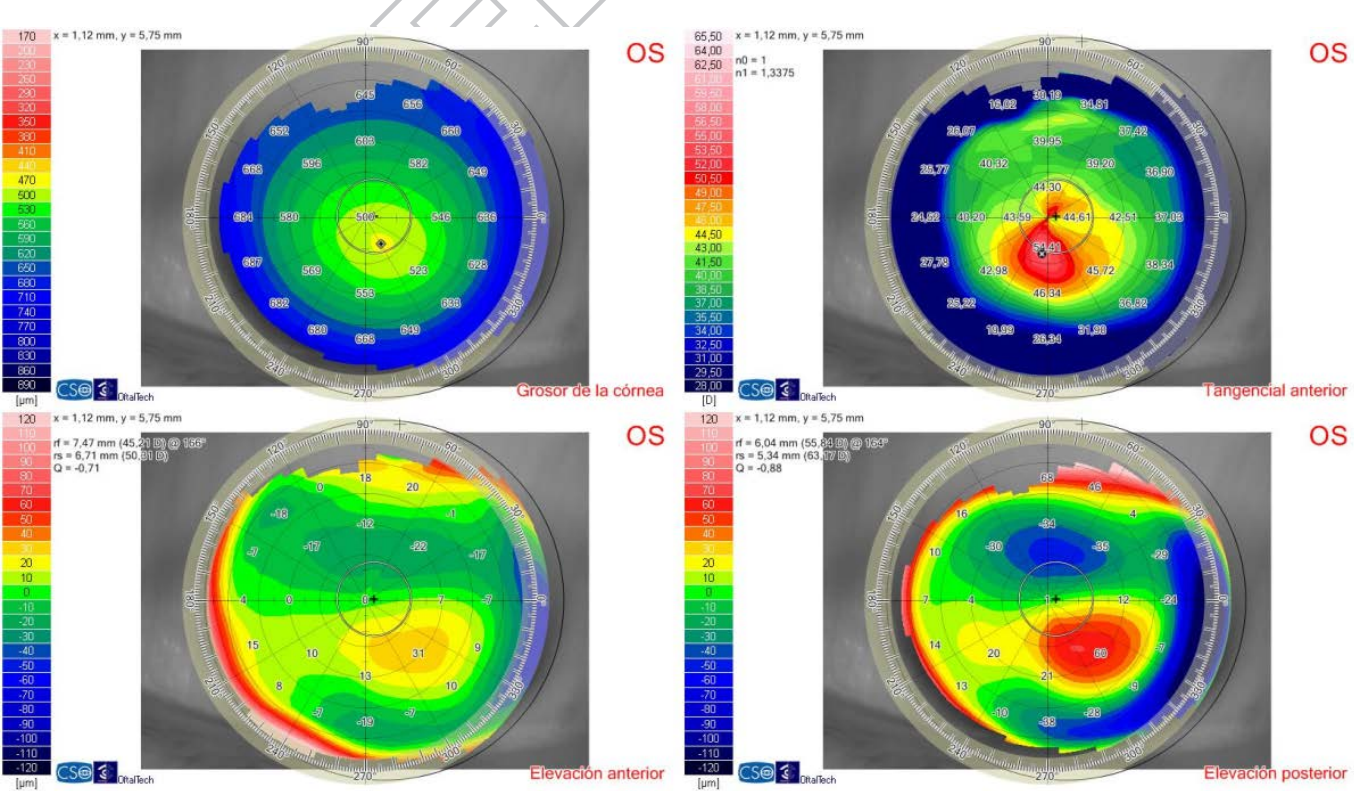


Figure 3.- Anterior corneal aberrometric analysis in a keratoconus eye with the Scheimpflugbased topography system Sirius from CSO (Italy). Six maps are displayed from left to right and from up to bottom: total aberration map, higher order aberration map, astigmatism map, primary coma map, spherical aberration and residual orders map (higher order aberrations excluding primary coma and spherical aberration).
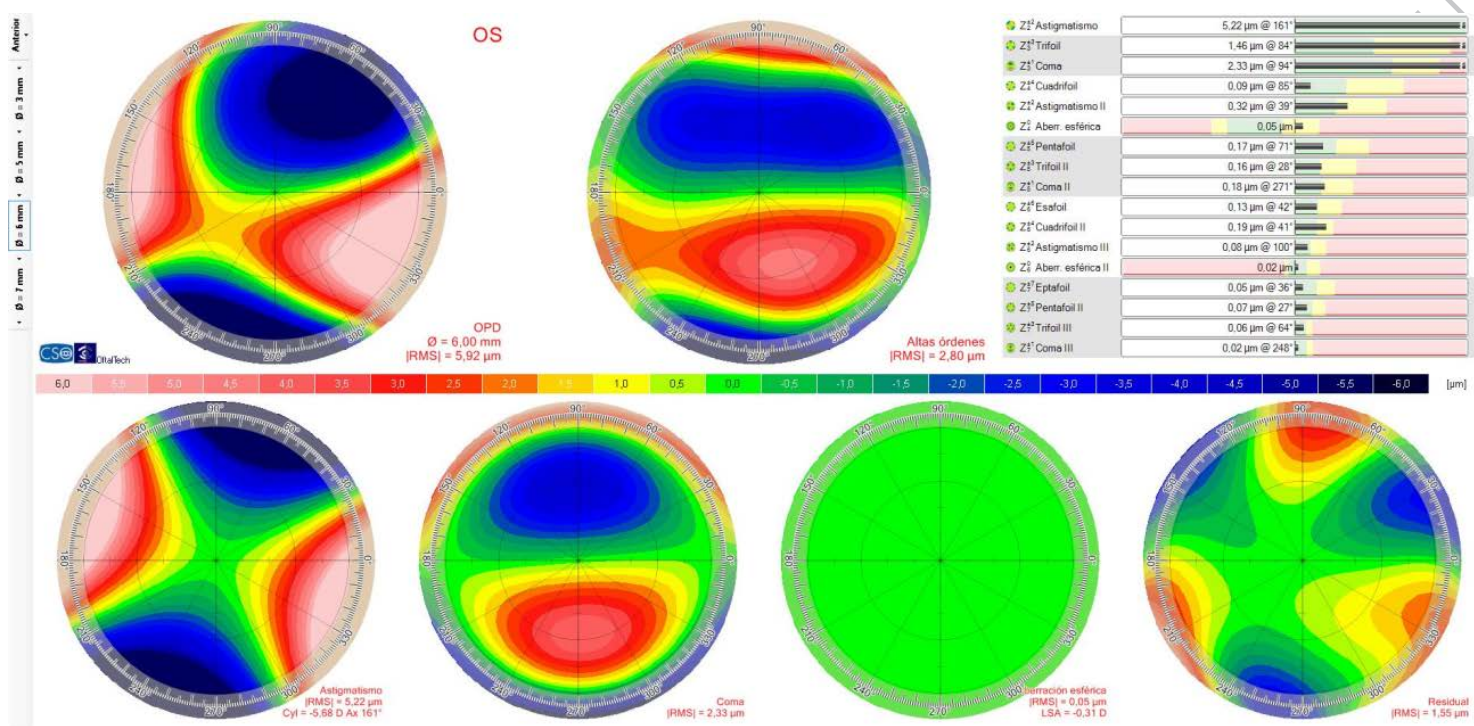
Figure 4.- Pseudokeratoconus due to an alteration of the tear film during the measurement procedure. Specifically, there was a break of tear film in the supero-nasal quadrant leadin to a false appearance of flattening and the consequently steepening of the cornea in the inferotemporal quadrant.

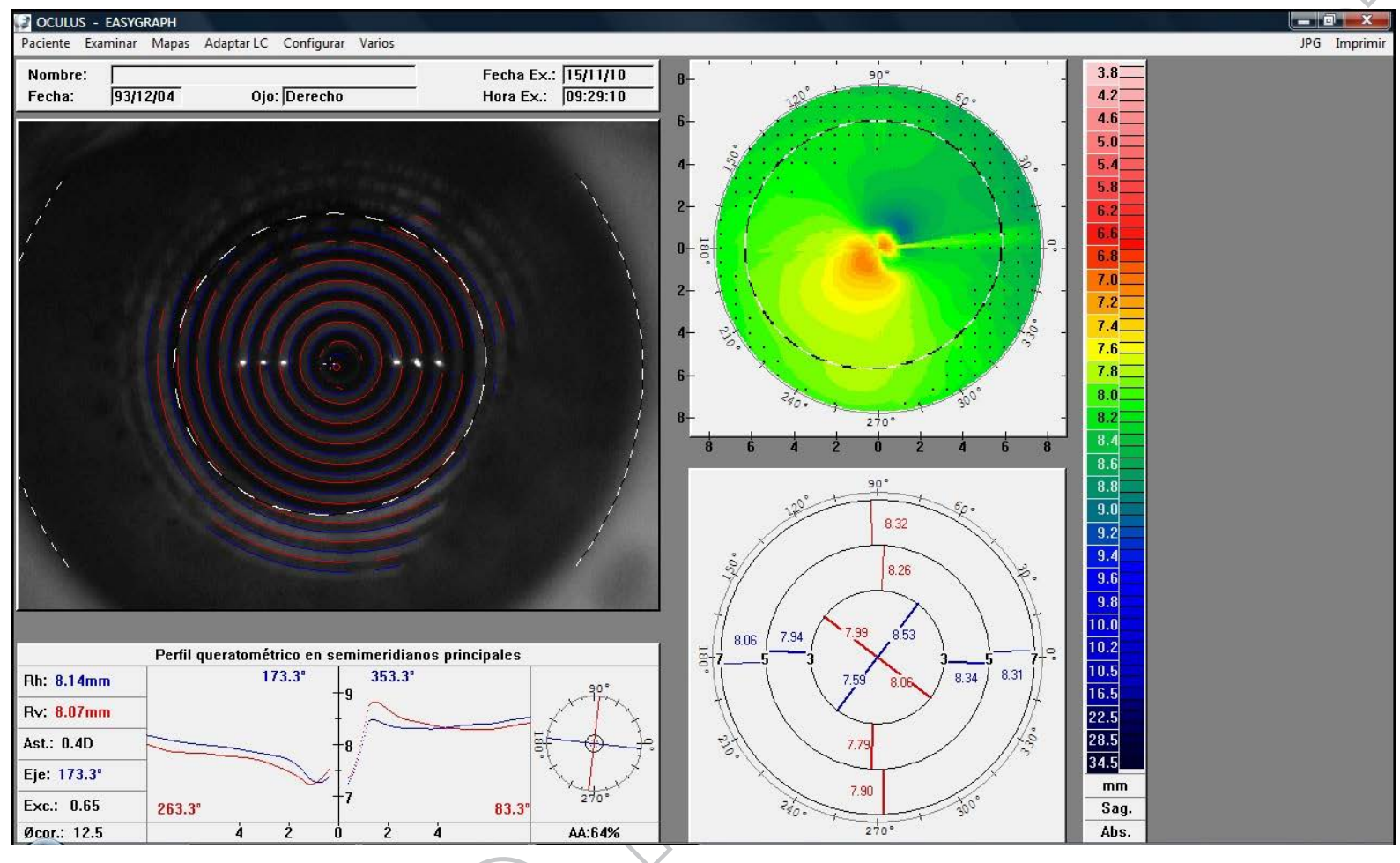


Figure 5.- Topographic map showing an infero-superior corneal asymmetry compatible with a pattern of keratoconus suspect in a patient wearing a silicone hydrogel contact lens. This map was normalized after the cessation of the lens during 1 week, suggesting that there was a superior pressure of the lens in the superior part of the corneal leading to this corneal asymmetry.

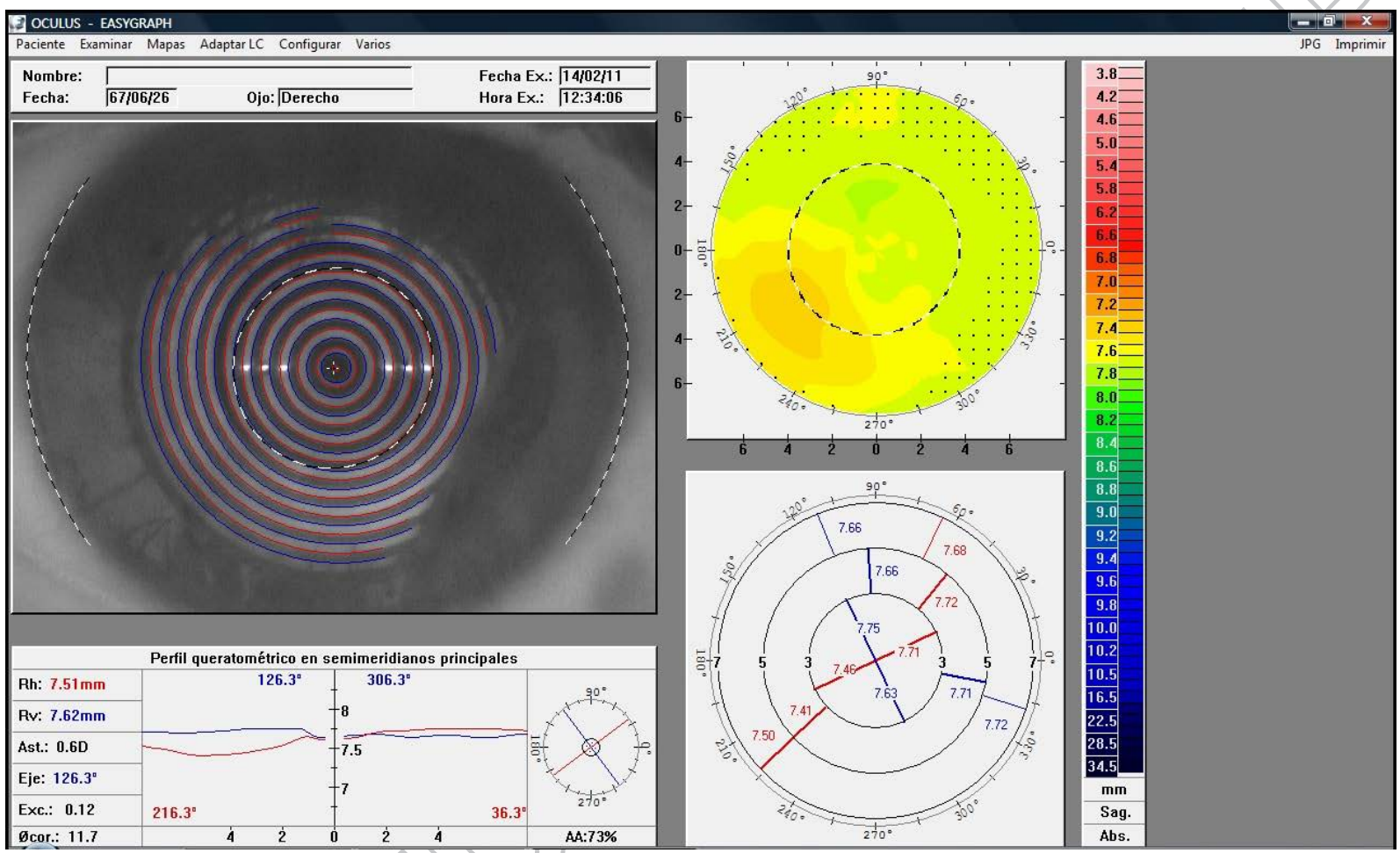

Figure 6.- Corneal topographic map showing an infero-superior asymmetry compatible with a

keratoconus in a cornea with a superior scar due to a trauma.
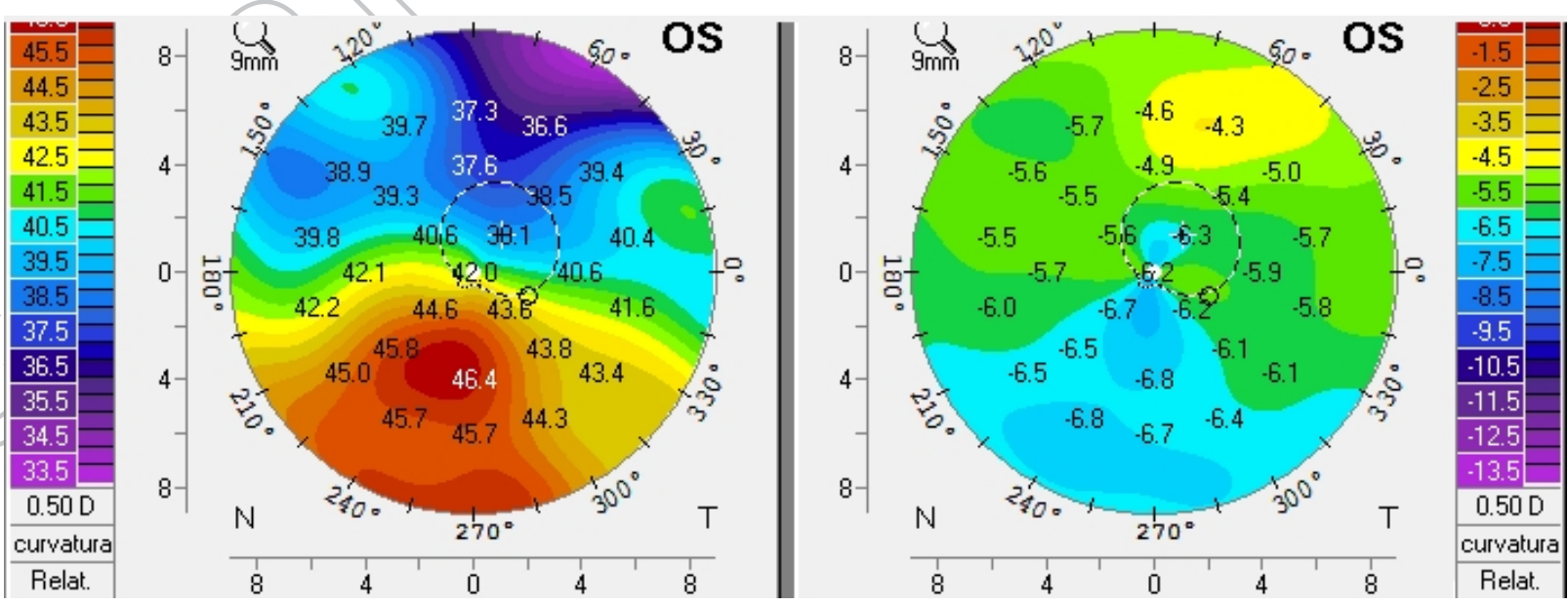
Table 1.- Diagnostic criteria reported for different topographic parameters.

\begin{tabular}{|c|c|c|c|}
\hline Parameter & $\begin{array}{l}\text { Cutoff or diagnostic } \\
\text { criteria }\end{array}$ & Sensitivity & Specificity \\
\hline $\begin{array}{c}\text { Surface Asymmetry Index } \\
\text { (SAI) }\end{array}$ & $>1$ & & \\
\hline $\begin{array}{l}\text { Corneal Irregularity } \\
\text { Measurement (CIM) }\end{array}$ & 1.10 to $5.00 \mu \mathrm{m}$ & & \\
\hline $\begin{array}{l}\text { Infero-superior (I-S) } \\
\text { asymmetry }\end{array}$ & $>1.8 \mathrm{D}$ & & \\
\hline KISA \% & $\geq 100$ & & \\
\hline $\begin{array}{c}\text { Keratoconus Prediction } \\
\text { Index (KPI) }\end{array}$ & $\geq 0.38$ & $86 \%$ & $100 \%$ \\
\hline $\begin{array}{c}\text { Mean keratometry (KM) } \\
+ \text { I-S }\end{array}$ & $\begin{aligned} \mathrm{KM} & >47.8 \mathrm{D} \\
\mathrm{I}-\mathrm{S} & >1.9 \mathrm{D}\end{aligned}$ & $96 \%$ & \\
\hline $\begin{array}{c}\text { Mean toric keratometry } \\
\text { (MTK) }\end{array}$ & $\begin{array}{c}\text { From } 36.0 \text { to } 41.7 \\
\text { and from } 47.3 \text { to } 60.0 \\
\text { D }\end{array}$ & & \\
\hline $\begin{array}{c}\text { Surface Regularity Index } \\
\text { (SRI) }\end{array}$ & $>1.55$ & & \\
\hline Keratoconus Index (KCI) & $>0 \%$ & $98 \%$ & $99 \%$ \\
\hline $\begin{array}{c}\text { High rate of steepening } \\
\text { (HRS) }\end{array}$ & $1.40 \mathrm{D} / \mathrm{mm}$ & $95.7 \%$ & $96.4 \%$ \\
\hline $\begin{array}{l}\text { Index of surface variation } \\
\text { (ISV) }\end{array}$ & $\begin{array}{c}\geq 0.37 \text { suspicious } \\
\geq 0.41 \text { pathological }\end{array}$ & & \\
\hline $\begin{array}{c}\text { Index of vertical } \\
\text { asymmetry (IVA) }\end{array}$ & $\begin{array}{l}\geq 0.28 \text { suspicious } \\
\geq 0.32 \text { pathological }\end{array}$ & & \\
\hline Keratoconus Index (KI) & $>1.07$ & & \\
\hline $\begin{array}{c}\text { Center Keratoconus } \\
\text { Index (CKI) }\end{array}$ & $\geq 1.03$ & & \\
\hline $\begin{array}{l}\text { Smallest radius of } \\
\text { curvature (RMin) }\end{array}$ & $<6.71$ & & \\
\hline $\begin{array}{l}\text { Index of height } \\
\text { asymmetry (IHA) }\end{array}$ & $\begin{array}{l}\geq 19 \text { suspicious } \\
>21 \text { pathological }\end{array}$ & & \\
\hline $\begin{array}{c}\text { Index of height } \\
\text { decentration (IHD) }\end{array}$ & $\begin{array}{l}\geq 0.014 \text { suspicious } \\
>0.016 \text { pathological }\end{array}$ & & \\
\hline $\begin{array}{l}\text { Aberration coefficient } \\
\text { (ABR) }\end{array}$ & $\geq 1$ & & \\
\hline $\begin{array}{c}\text { Topography disparity } \\
\text { (TD) }\end{array}$ & 1.64 & $93.3 \%$ & $92.1 \%$ \\
\hline
\end{tabular}

